\title{
IDENTIFICACIÓN DE ESPECIES CÁRNICAS EN PRODUCTOS CÁRNICOS COCIDOS: UTILIZACIÓN DE SDS-PAGE COMO MÉTODO DE SCREENING
}

\section{MEAT SPECIES IDENTIFICATION IN COOKED MEAT PRODUCTS: USING SDS-PAGE AS SCREENING METHOD}

\author{
Laura López B., María Binaghi J., Carola Greco B., \\ María Mambrín C., Mirta Valencia E. \\ Cátedra de Bromatología, Facultad de Farmacia y Bioquímica, \\ Universidad de Buenos Aires. Buenos Aires, Argentina.
}

\begin{abstract}
It is necessary to have methodologies for the detection of meat species used in meat products in order to establish possible adulterations. Twenty cooked meat products produced in pilot plants or commercially available products were analyzed in order to evaluate the SDS-PAGE electrophoresis methodology as a screening method to identify the meat species used. The results found by electrophoresis were compared with an immunochemical method (ELISA kits for detection of pork, beef and poultry). SDS-PAGE methodology allowed the detection of beef, pork, chicken and lor turkey proteins in most samples. When some of these species were present in low proportion this methodology was not able to detect them. SDS-PAGE method has the advantage that allows the detection of proteins of different meat species in only one electrophoresis run while with the ELISA method it is necessary to analyze the same sample with different species identification kits to confirm the presence of the species used. Key words: SDS-PAGE; meat species; ELISA; identification; meat products.
\end{abstract}

Este trabajo fue recibido el 24 de Agosto de 2010 y aceptado para ser publicado el 15 de Abril de 2011.

\section{INTRODUCCIÓN}

En la República Argentina los organismos de control y los productores de alimentos requieren metodologías accesibles para la identificación y cuantificación de materias primas proteicas en una amplia gama de alimentos que deberían ser controlados. Internacionalmente se han desarrollado kits de ELISA y de reacción en cadena de la polimerasa (PCR), tanto para alimentos crudos como cocidos que permiten detectar algunas materias primas proteicas. En el caso de PCR, los kits tienen un costo muy elevado y es necesario contar con un laboratorio adecuado que permita realizar este tipo de metodología. Los kits de ELISA son mas sencillos y se pueden realizar en cualquier laboratorio de control de alimentos. Sin embargo, el costo de los mismos también es elevado y es necesario recurrir a diversos kits para las distintas materias primas que se deben controlar.
La electroforesis en gel de poliacrilamida con dodecilsulfato de sodio (SDS-PAGE) permite la detección y cuantificación de una amplia variedad de materias primas proteicas en alimentos de distinto origen tanto crudos como cocidos (1-4).

El Código Alimentario Argentino permite en la elaboración de diferentes productos cárnicos el empleo de distintas especies cárnicas, las cuales deben estar declaradas en la lista de ingredientes. Entre los productos cocidos hay algunos como el jamón cocido, la paleta de cerdo cocida, el lomo de cerdo cocido y los fiambres cocidos de pata de cerdo, de paleta de cerdo y de lomo de cerdo, que sólo pueden ser elaborados con esta especie cárnica. En productos como fiambres para emparedado se autoriza el empleo de trozos y/o recortes de carne de especies de faena permitida (5). En este tipo de fiambres se pueden encontrar distintas especies cárnicas (vacuna, 
porcina, pollo, pavo) o mezclas de las mismas, como por ejemplo mezclas de carne porcina y carne vacuna o de carne porcina y pollo.

Por lo expuesto, en el análisis de productos cárnicos es necesario contar con metodologías accesibles que permitan la detección de las especies cárnicas utilizadas en su elaboración a fin de establecer posibles adulteraciones. No existe en la República Argentina metodología oficial para este propósito.

En trabajos previos, en productos cárnicos crudos elaborados con una única especie cárnica la metodología SDS-PAGE permitió identificar especies vacuna o porcina (6-7). Trabajando con sistemas modelo crudos de mezclas de carne vacuna con carne porcina esta metodología permitió detectar ambas especies cárnicas en productos crudos elaborados con mezclas cárnicas. Con dichos sistemas modelo se estableció un nivel de detección de $10 \%$ de una especie en mezcla con la otra (8).

A nivel internacional existen métodos inmunoquímicos (kits de enzimoinmunoensayos, ELISA) que permiten la detección cualitativa de especies cárnicas. Hay disponibles kits comerciales para especies bovina, porcina, ovina y aves de corral (9-10). Los kits utilizan anticuerpos contra proteínas musculares estables al calor. Dichos anticuerpos intervienen en un enzimoinmunoensayo de tipo no competitivo.

Con la finalidad de evaluar la metodología SDSPAGE como método de screening para identificar la/ las especies cárnicas utilizadas en la formulación de productos cárnicos, el presente trabajo se analizó con esta metodología productos cárnicos cocidos elaborados en plantas piloto o comerciales. Los resultados hallados por electroforesis se compararon con un método inmunoquímico, ELISA para detección de especie porcina, ELISA para detección de especie vacuna y ELISA para detección de aves de corral.

\section{MATERIALES Y MÉTODOS Muestras}

Se analizaron veinte productos cárnicos cocidos (PC). La denominación de cada producto y las especies cárnicas declaradas en cada uno se presentan en la tabla 1.

Las muestras PC 8, 10, 15, 16, 17, 18, 19 y 20 fueron diseñadas y elaboradas por empresas que comercializan materias primas proteicas para la industria cárnica. Dichas empresas colaboraron con estas muestras para la realización del presente trabajo aportando la formulación de cada una de ellas. El resto de las muestras analizadas correspondían a productos comerciales que declaraban las especies cárnicas utilizadas para su elaboración en su lista de ingredientes.
Se utilizaron como controles de las muestras analizadas carne vacuna, carne porcina, pavo y pollo.

\section{Determinaciones analíticas Análisis electroforético}

Desgrasado/deshidratado de las muestras: El desgrasado/deshidratado de las muestras y de los controles, previamente picados en procesadora, se realizó con acetona. Se suspendió el producto cárnico en relación 1/10 y se homogeneizó en VirTis modelo 23 a baja velocidad durante 5 minutos. Posteriormente se centrifugó a 1200 rpm durante 20 minutos y se descartó el sobrenadante. Las muestras fueron desgrasadas con acetona dos veces.

Extracción de proteínas totales: Se utilizó buffer Tris-ClH 0,0625M (pH: 6,8) con $3 \%$ de SDS y $2 \%$ de 2-ME (solución extractiva de proteínas totales). Se pesaron $30 \mathrm{mg}$ de producto cárnico desgrasado/ deshidratado con acetona y se extrajeron con $2 \mathrm{~mL}$ de solución extractiva por calentamiento en baño de agua a $100^{\circ} \mathrm{C}$ durante 5 minutos con agitación y posterior centrifugación a $2500 \mathrm{rpm}$ durante 15 minutos.

Electroforesis: Se utilizó básicamente el sistema de Laemmli (11). Se trabajó con geles de poliacrilamida en sistema discontinuo. El gel de separación se preparó con $10 \%$ de acrilamida en una solución 1,5 M Tris-ClH con $0,4 \%$ de SDS (pH: 8,8). El gel de concentración se preparó con $3 \%$ de acrilamida en una solución 0,5 M Tris-ClH con 0,4\% de SDS (pH: 6,8). Se utilizó como buffer de corrida una solución 0,025 M Tris; 0,192 M glicina (ácido aminoacético) y $0,1 \%$ dodecilsulfato de sodio.

La electroforesis se realizó con equipo Mini Protean ${ }^{\circledR}$ Tetra cell de BioRad a $180 \mathrm{~V}$ durante 45 minutos. La tinción se realizó con Coomassie Brilliant Blue R 250. Las resoluciones proteicas obtenidas se densitometraron con equipo Shimadzu Dual - Wavelength Chromatogram Scanner Model CS - 910. Se trabajó con longitud de onda de máxima absorción de 550 nm y de mínima absorción utilizada como referencia de $400 \mathrm{~nm}$. La adquisición de datos se realizó con el programa Chromatography Station CSW de DataApex Ltd. Todas las muestras fueron analizadas por duplicado.

\section{Método inmunoquímico}

Extracción de proteínas para el ELISA: se preparó una solución salina, $9 \mathrm{~g}$ de cloruro de sodio /L en agua pura. Se pesaron 25 gramos de muestras picadas en procesadora, y se agregaron $100 \mathrm{~mL}$ de solución salina. Se agitaron 15 minutos a temperatura ambiente en un baño con agitación y luego se dejaron 15 minutos en reposo. Se trasvasaron aproximadamente $15 \mathrm{~mL}$ a tubos Falcon y se centrifugaron a $2500 \mathrm{~g}$ durante 15 minutos. 
Se trasvasaron los sobrenadantes a tubos eppendorf y se conservaron a $2-8^{\circ} \mathrm{C}$ hasta su análisis, dentro de las 36 horas.

ELISA: se utilizaron tres kits comerciales para la determinación cualitativa de especies en productos cocidos: Biokits (cooked) species identification Test Kit pork, beef and poultry de Gen-Probe. De acuerdo con las especificaciones de cada kit los límites de detección están en el orden del $1 \%$.

El ensayo se realizó siguiendo las instrucciones de los kits comerciales (10). Las absorbancias de todos los micropozos se obtuvieron en un lector de ELISA Rayto modelo RT-2100 C a $450 \mathrm{~nm}$. Todas las muestras fueron analizadas por duplicado, incluyendo además un control positivo y dos controles negativos. En la determinación de especie porcina se utilizó el control positivo porcino y los controles negativos vacuno y pollo. En la determinación de especie vacuna se utilizó el control positivo vacuno y los controles negativos porcino y pollo. En la determinación de aves de corral se utilizó el control positivo pollo y los controles negativos porcino y vacuno. Con las absorbancias (Abs) de los controles negativos (CN1 y CN2) se calculó un valor cut off de acuerdo con las especificaciones de los kits utilizados:

$$
\text { Cut off }=\frac{(\mathrm{Abs} \mathrm{CN} 1+\mathrm{Abs} \mathrm{CN} 2)}{2} \times 2,5
$$

La absorbancia promedio de la muestra se comparó con ese valor cut off.

\section{RESULTADOS}

En la figura 1 se presentan los densitogramas correspondientes a proteínas totales de carnes vacuna, porcina, pollo y pavo. Si bien cada una de estas muestras presenta un patrón común, por ejemplo por la presencia de miosina de 200000 D (M) y actina de 46000 D (A) hay diferentes picos que resultan característicos de cada especie cárnica. En el densitograma de carne vacuna se señalan los picos V1 de 66000 D y V2 de 57000 D; en el de carne porcina se señalan P1 de 63600 D y P2 de 61300 D; en el de pollo se señala Po de 51100 D y en el de pavo se señala Pa de 49000 D. Si bien el perfil de carne de pollo es muy similar al de carne de pavo en esta última el pico Pa tiene menor peso molecular que el pico Po de la carne de pollo; la posición de estos picos permite distinguir el origen de una u otra especie cárnica.

En la tabla 1 se presentan los resultados obtenidos por electroforesis y por ELISA de los 20 productos cárnicos cocidos analizados. A modo de ejemplo, en las figuras 2 y 3 se presentan los densitogramas correspondientes a las muestras PC 2 y PC 8, 9, 10, 12, 13 y 14, respectivamente. En los densitogramas de cada una de las muestras de estas figuras se señalan los picos característicos de las especies cárnicas detectadas por electroforesis.

\section{DISCUSIÓN}

De acuerdo con trabajos anteriores la metodología electroforética permite la detección de proteínas extrínsecas en productos cárnicos (1-4). En algunos de los productos analizados en el presente trabajo se detectaron proteínas extrínsecas, sin embargo debido al objetivo planteado se discutirán los resultados obtenidos en lo que concierne a la identificación de las especies cárnicas detectadas y sólo se hará referencia a la detección de plasma por su posible superposición con picos característicos de la carne vacuna. El plasma presenta dos picos característicos de pesos moleculares 66000 y $57000 \mathrm{D}$, que coinciden con los picos característicos de carne vacuna (V1 y V2) que permiten su detección en mezcla con carne porcina. Sin embargo la presencia de plasma se evidencia por una mayor proporción del pico de $66000 \mathrm{D}$ con respecto al de $57000 \mathrm{D}$ (1).

La metodología electroforética permitió, en la mayoría de las muestras diseñadas y elaboradas por empresas que comercializan materias primas proteicas para la industria cárnica (muestras PC 8, 10, 15, 16, 17, 18, 19 y 20), detectar las especies cárnicas empleadas en su formulación (tabla 1).

En la muestra PC 15 que declaraba además de carne porcina y de plasma, carne vacuna, se detectó la presencia de proteínas de cerdo y de plasma. Esta metodología no permite diferenciar plasma vacuno de plasma porcino ya que ambas materias primas presentan igual patrón electroforético (1). Paralelamente a esta muestra se analizó un sistema modelo de mezcla carne de cerdo/ carne vacuna ( $75 \%$ carne de cerdo/ $25 \%$ carne vacuna) en el que se pudieron identificar claramente picos característicos de ambas especies cárnicas. Debido a que los picos característicos de plasma coinciden con los picos de carne vacuna (V1 y V2) que permiten su detección en mezcla con carne porcina (P1 y P2), no es posible en esta muestra confirmar la presencia de carne vacuna.

En la muestra PC 18 por electroforesis se detectaron proteínas de pollo pero no fue posible detectar proteínas de cerdo. Este producto fue elaborado con $60 \%$ de carne de pollo y $40 \%$ de recorte de cerdo. Evidentemente el recorte de cerdo tenía una baja proporción de carne de cerdo por lo que la sensibilidad del método electroforético no fue suficiente para detectar estas proteínas.

La muestra PC 20 fue elaborada con diferentes cortes de carne de cerdo y tenía además agregado de proteínas añadidas de origen vacuno (gelatina y plasma). La metodología electroforética permitió detectar las proteínas de cerdo y plasma en baja proporción. 


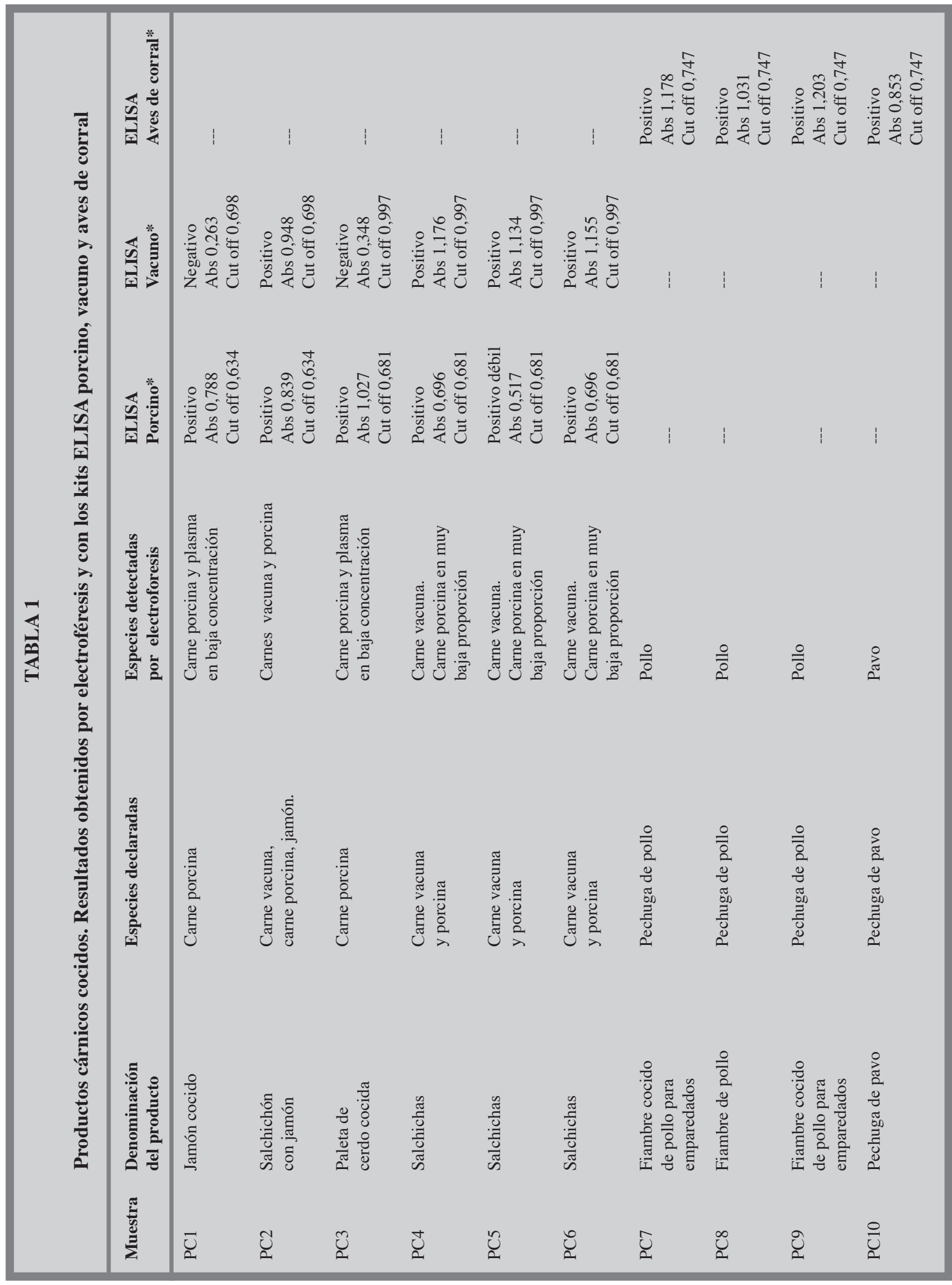




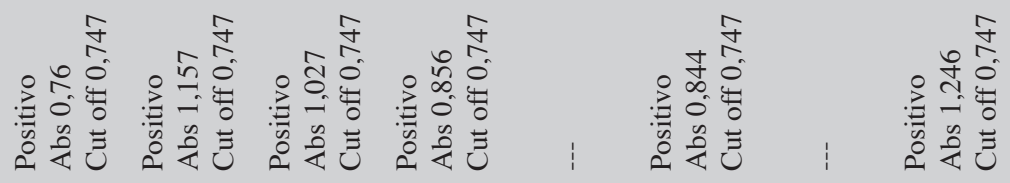

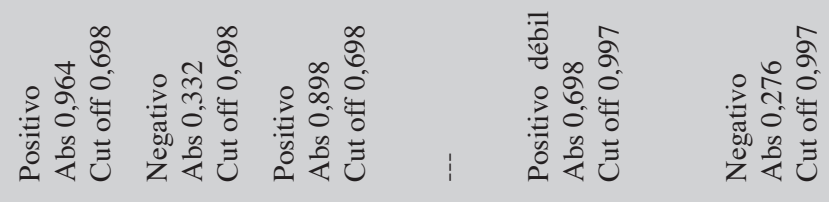

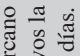

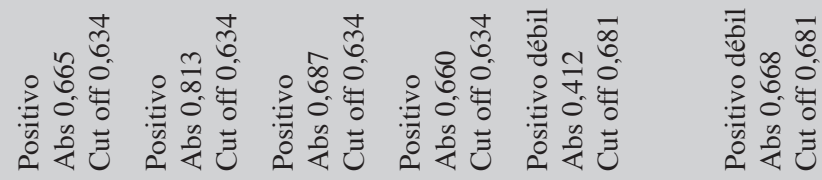

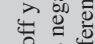

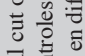

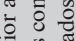

늘 을

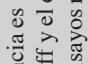

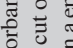

政

\&

t)

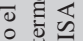

雹 四

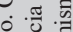

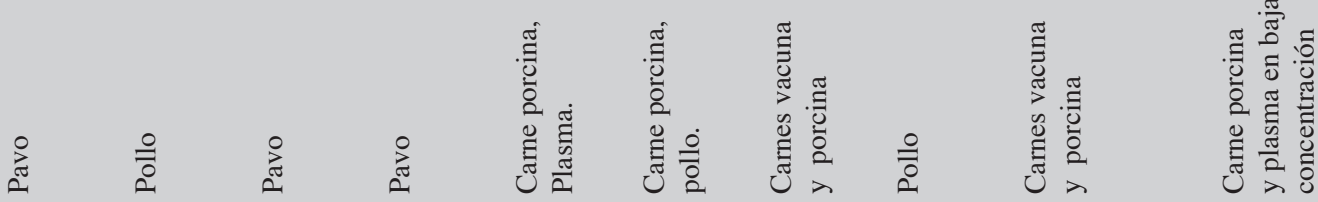

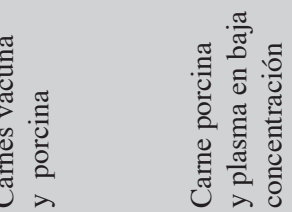

㱐

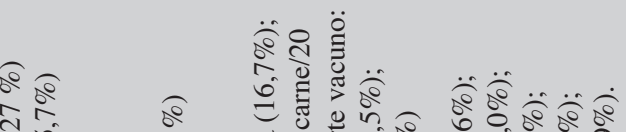

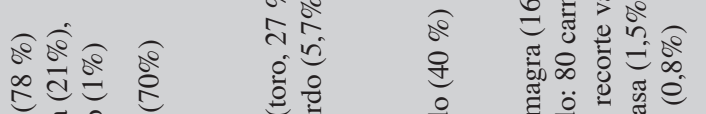

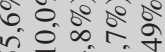

o d च

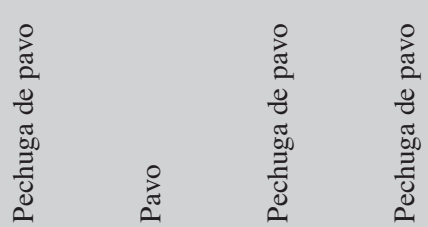

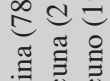

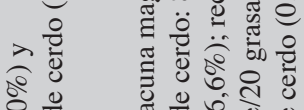

휴윻윻

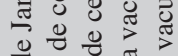

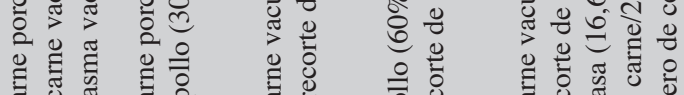

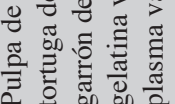

o.

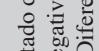

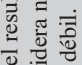

응

t

๕.

ะ

혼

$\stackrel{\infty}{u}$

$\stackrel{a}{u}$

¿ิ

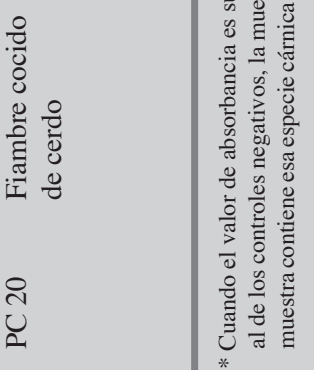


En las muestras PC 8, 10, 16, 17 y 19 fueron detectadas las especies cárnicas utilizadas en su elaboración.

Con respecto a las muestras comerciales, la metodología electroforética permitió en las muestras PC1 y 3 la detección de proteínas de cerdo y de plasma, no declarado, en baja proporción. En las muestras PC 4, 5 y 6 se detectó claramente la presencia de proteínas vacunas pero la presencia de proteínas de cerdo se observó en muy baja proporción. En la muestra PC 12 que declaraba pavo se identificaron proteínas de pollo y no de pavo. En el resto de las muestras comerciales se detectaron por electroforesis las especies cárnicas declaradas en los respectivos rótulos (tabla 1).

Los resultados obtenidos empleando los ELISA para vacuno y para porcino corroboraron en general los resultados obtenidos por la metodología electroforética (tabla 1). En las muestras en las que se detectó plasma (PC 1 y 3) sólo dio positivo el ELISA porcino. Trabajando con sistemas modelo de carne de cerdo con agregado de plasma vacuno en niveles de 0,$5 ; 1$ y $2 \%$ y con plasma vacuno solo, se observó que el resultado del ELISA vacuno fue negativo en todos los casos (resultados no

\section{FIGURA 1}

Densitogramas correspondientes a proteínas totales de carnes vacuna y porcina, de pavo y de pollo, separadas por SDS-PAGE.

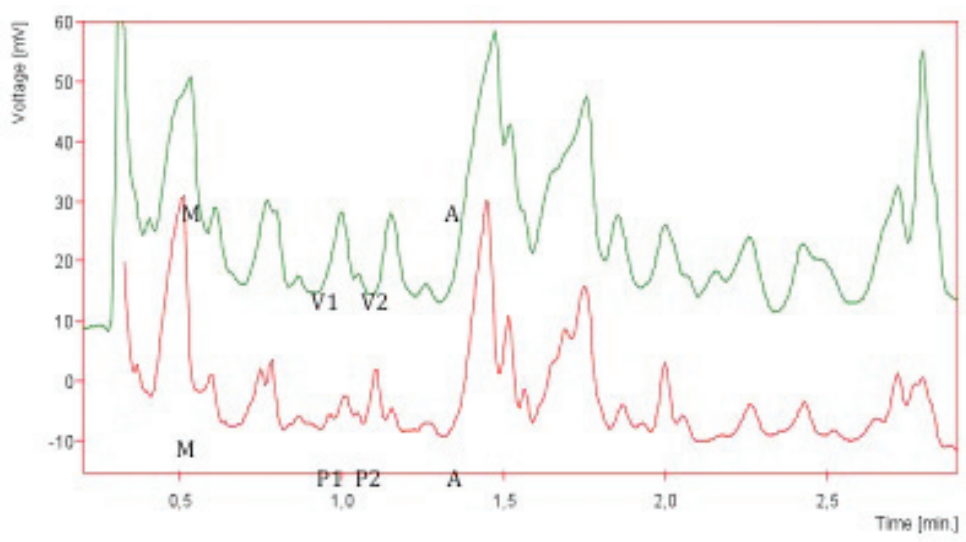

Carne vacuna

Carne porcina

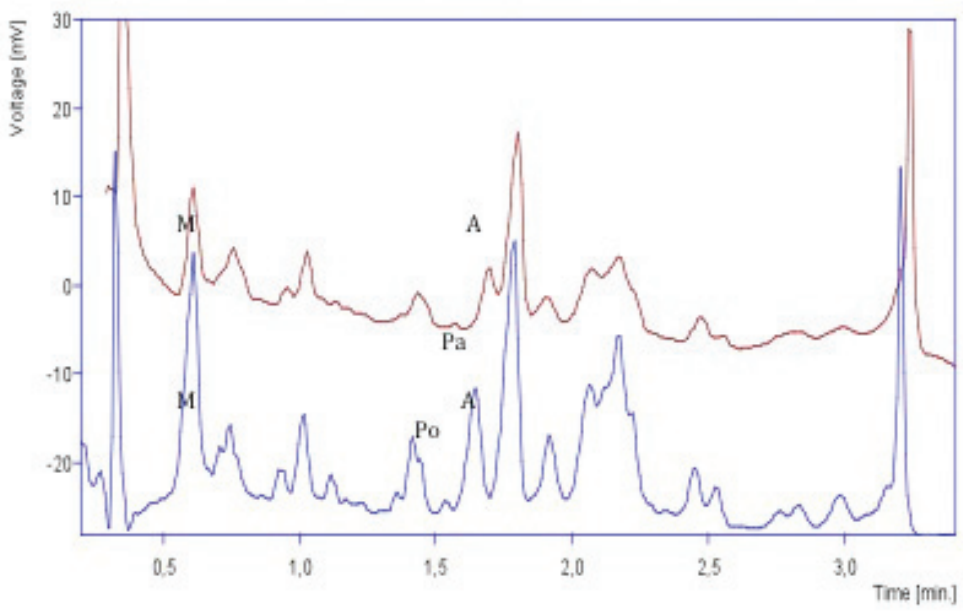

Pavo

Pollo

Picos característicos de carne vacuna: V1: 66000 D y V2: 57000 D. Picos característicos de carne porcina: P1: 63600 D y P2: 61300 D. Pico característico de pavo: Pa: 49000 D. Pico característico de pollo: Po: 51100 D. Picos comunes a ambas especies cárnicas, M: miosina (200000 D), A: actina (46000 D). 
publicados). Esto nos indica que este kit no permite detectar proteínas de plasma vacuno. En las muestras PC 4, 5 y 6 ambos kits dieron resultados positivos, sin embargo las absorbancias de las tres muestras analizadas con el kit para porcino dieron muy cercanas al cut off lo que nos estaría indicando una baja proporción de carne porcina, resultados que concuerdan con los hallados por electroforesis. En la muestra PC 15 ambos ELISA, vacuno y porcino, dieron positivos. Estos resultados confirman la presencia de carne vacuna que no pudo ser detectada por electroforesis debido a la presencia de plasma. En este tipo de muestras puede resultar conveniente recurrir a ambas metodologías, el método de ELISA para confirmar ambas especies cárnicas, y el método electroforético para confirmar la presencia de plasma que no es detectado con el ELISA.

En la muestra PC 19 los kits de ELISA tanto vacuno como porcino dieron valores de absorbancia inferiores al cut off pero superiores a los respectivos controles negativos. Esto puede deberse a la baja proporción de carne tanto vacuna como porcina que tendría este fiam- bre. Si bien por electroforesis ambas especies cárnicas fueron detectadas en este producto se observó una baja intensidad de todos los picos cárnicos presentes.

En la muestra PC 20 resultó positivo el ELISA para porcino aunque el valor de absorbancia obtenido fue muy cercano al cut off, lo que indica la presencia de carne porcina en baja proporción. El ELISA para vacuno resultó negativo. Esto indica que las proteínas vacunas agregadas (gelatina y plasma) no fueron detectadas por el método de ELISA. Por electroforesis se detectó la presencia de proteínas de carne de cerdo y de plasma.

En algunos fiambres para emparedado se observó una alta proporción de tejido conectivo y de grasa y el análisis electroforético de ese tipo de productos demostró que la proporción de carne es baja; ello se manifiesta por una baja intensidad de picos característicos de carne, ya sea vacuna o porcina. Con el método ELISA la baja proporción de la carne utilizada en estos productos se evidencia por un valor de absorbancia para la especie cárnica próximo o incluso inferior al cut off. Por este motivo, la interpretación de los resultados obtenidos

\section{FIGURA 2}

Densitogramas correspondientes a proteínas totales de la muestra PC 2 y de carnes vacuna y porcina y de jamón cocido, utilizados como control, separadas por SDS-PAGE.

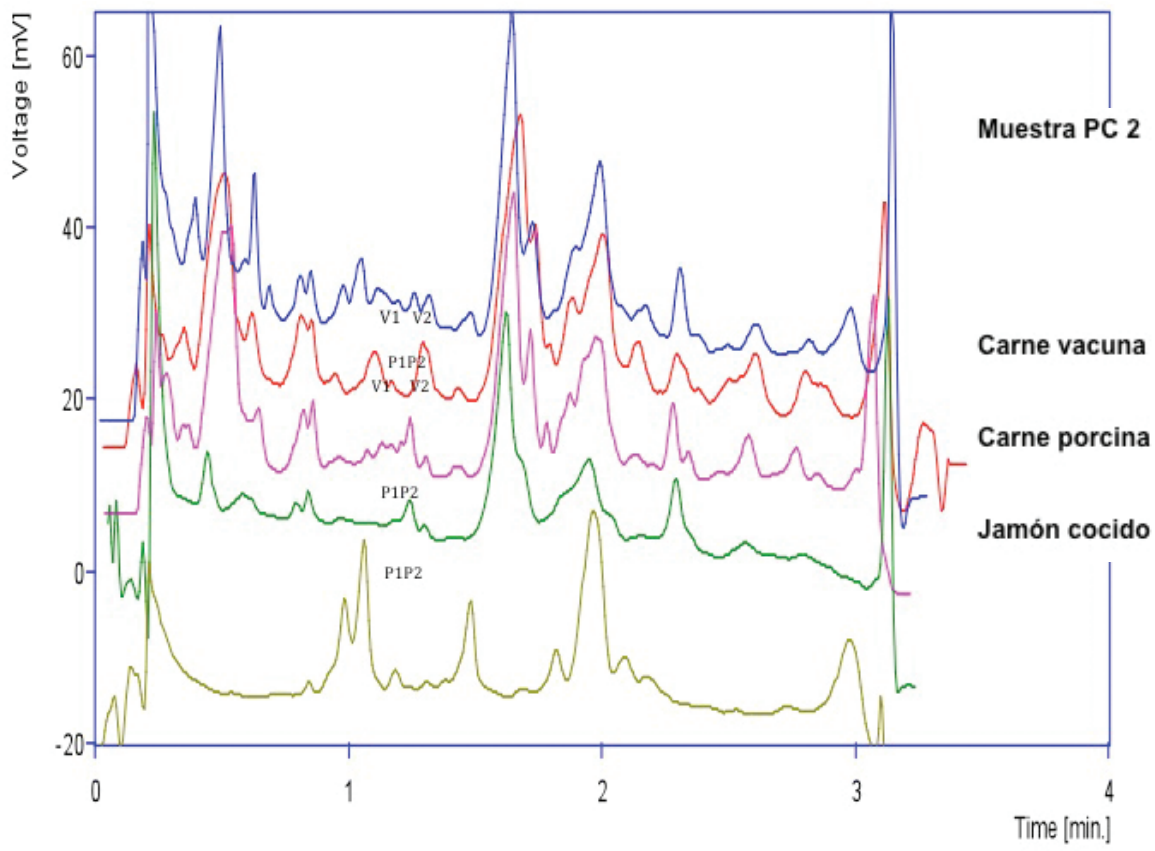

V1 y V2: picos característicos de carne vacuna. P1 y P2: picos característicos de carne porcina. 
por ELISA debe ser cuidadosa: a) cuando el valor de absorbancia es superior al cut off sin duda la muestra contiene la especie cárnica en estudio y el resultado del ELISA se debe considerar positivo; b) cuando el valor de absorbancia es inferior al cut off y cercano a la de los controles negativos la muestra no contiene esa especie cárnica y el resultado del ELISA se debe considerar negativo; c) cuando el valor de absorbancia es intermedio entre el cut off y el control negativo la muestra contiene esa especie cárnica pero en baja proporción y el resultado del ELISA se debe considerar positivo débil.

Con respecto a los productos cárnicos cocidos elaborados con pollo o pavo (PC 7 a 14) el ELISA de aves de corral dio positivo en todos los casos. Este kit, destinado a aves de corral, evidentemente no distingue pollo de pavo. La metodología electroforética sí permite distinguir ambas especies cárnicas como se mencionó anteriormente.

Por último en los productos PC 16 y 18 que estaban elaborados con cerdo y pollo, los kits porcino y de aves de corral detectaron la presencia de cerdo y de pollo en ambas muestras. La metodología electroforética permitió la detección de proteínas de cerdo en PC 16 pero no en PC 18. Esto se debe a la diferente proporción de cerdo en ambas muestras (70\% de carne de cerdo en PC 16 y $40 \%$ de recorte de cerdo en PC 18).

De acuerdo con los resultados obtenidos, la metodología electroforética permitió la detección de proteínas de carne vacuna, porcina, de pollo y/o de pavo en la mayoría de las muestras analizadas. Sólo en algunas muestras que contenían alguna de las especies cárnicas en baja proporción esta metodología no permitió la detección de esa especie cárnica. En el caso de muestras que contenían carne vacuna y que además contenían plasma vacuno o porcino se observó que se dificulta con esta metodología la detección de la carne vacuna.

La metodología electroforética tiene como ventaja que permite en una sola corrida detectar la presencia de proteínas de diferentes especies cárnicas, mientras que con la metodología ELISA es necesario analizar una misma muestra con los diferentes kits de especies cárnicas para confirmar la presencia de las especies

\section{FIGURA 3}

\section{Densitogramas correspondientes a proteínas totales de los productos cárnicos cocidos PC 8, 9, 10, 12, 13 y 14, separadas por SDS-PAGE.}

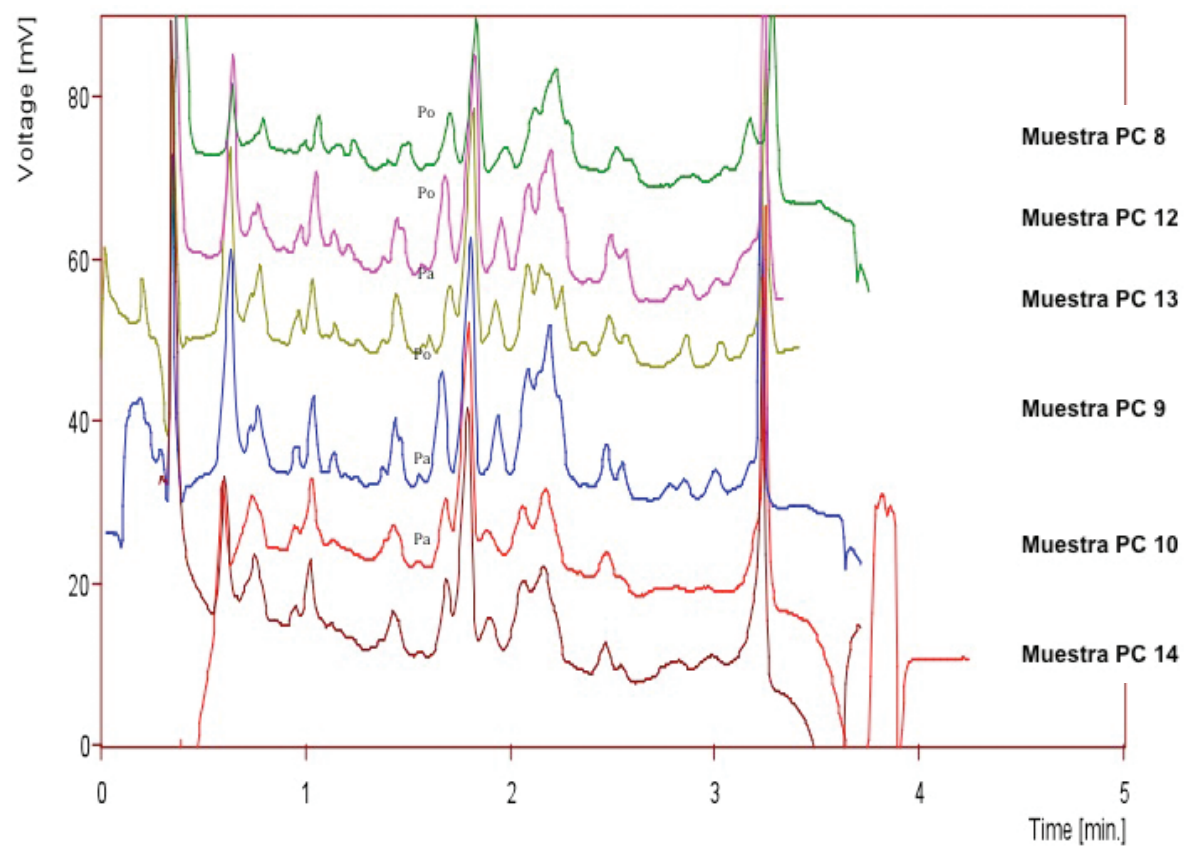

Po: pico característico de pollo. Pa: pico característico de pavo. 
utilizadas. Además, la metodología electroforética permite la detección de diferentes proteínas extrínsecas (soja, leche, caseinato, trigo, plasma, suero lácteo) en la misma corrida electroforética (1 y 4). En algunos de los productos analizados en el presente trabajo fueron detectadas varias de las proteínas mencionadas, algunas declaradas en los rótulos y otras no declaradas (resultados no mostrados).

\section{CONCLUSIONES}

Se propone a la metodología electroforética SDSPAGE como método de screening para el análisis de productos para verificar el origen de las especies cárnicas utilizadas en la formulación. En el caso de que una especie cárnica declarada no sea detectada por el método electroforético se puede recurrir al kit de ELISA de la especie en cuestión para confirmar su presencia ya que este presenta mayor sensibilidad. Esto permitiría abaratar los costos de este tipo de análisis.

\section{RESUMEN}

Es necesario contar con metodologías que permitan la detección de las especies cárnicas utilizadas en la elaboración de productos cárnicos a los fines de establecer posibles adulteraciones. Con la finalidad de evaluar SDS-PAGE como método de screening para identificar la/las especies cárnicas utilizadas, en el presente trabajo, se analizaron veinte productos cárnicos crudos o cocidos elaborados en plantas piloto o comerciales. Los resultados hallados por electroforesis se compararon con un método inmunoquímico (ELISA). SDS-PAGE permitió la detección de proteínas de carne vacuna, porcina, de pollo y/o de pavo en las mayoría de las muestras analizadas. Sólo en algunas muestras que contenían alguna de las especies cárnicas en baja proporción, esta metodología no permitió su detección. SDS-PAGE tiene como ventaja poder detectar en una sola corrida la presencia de proteínas de diferentes especies cárnicas, mientras que con ELISA es necesario analizar una misma muestra con los diferentes kits de especies cárnicas para confirmar la presencia de las especies utilizadas.

Palabras clave: SDS-PAGE; especies cárnicas; ELISA; identificación; productos cárnicos.

Agradecimientos: A TecnoAlimenti SA y ARYSA SA por su colaboración con muestras de composición conocida para su análisis. Estas empresas no tuvieron un rol en el diseño del estudio, recolección de la información, análisis de los resultados, interpretación de la información o escritura del artículo. Los autores del artículo tuvieron acceso completo a toda la información del estudio y la responsabilidad final del envío a publi- cación del artículo.

Este trabajo fue parcialmente financiado por UBACyT B418.

Dirigir la correspondencia a:

Profesora

Laura Beatriz López

Cátedra de Bromatología.

Facultad de Farmacia y Bioquímica

Universidad de Buenos Aires.

Junín 956. 2do piso.

Buenos Aires,

Argentina

E-mail: laulop@ffyb.uba.an

\section{BIBLIOGRAFÍA}

1. López LB, Greco CB, Ronayne de Ferrer Py Valencia ME. Identificación de proteínas extrínsecas en jamones cocidos por SDS-PAGE: nivel de detección en sistemas modelo, Arch Latinoam Nutr 2006; 56 (3): $282-7$.

2. López LB, Greco CB y Valencia ME. Aplicación de SDS-PAGE a la identificación de proteínas en materias primas proteicas y alimentos procesados; Trabajos del X Congreso Congreso Argentino de Ciencia y Tecnología de Alimentos. [CD-ROM]. Mar del Plata. Argentina. Tomo IV. p 1551-8. 2006

3. López LB, Greco CB., Pellegrino NR., Giacomino $S$ y Valencia ME. Control bromatológico de productos cárnicos, verificación del cumplimiento de la legislación; Industria Cárnica Latinoam 147: $62-5.2007$

4. López L, Greco C, Binaghi J, Mambrín C y Valencia M. Análisis de fiambres comerciales: detección de especies cárnicas y de proteínas agregadas utilizando SDS-PAGE; En: Ciencia y Tecnología de los Alimentos: Avances en Análisis Físicos, Químicos y Sensoriales (Wunderlin D. y Borneo R. eds) Ministerio de Ciencia y Tecnología. Córdoba, Argentina. p 187-95. 2009

5. Código Alimentario Argentino, actualizado 2009. http://www.anmat.gov.ar/codigoa/Capitulo_VI_ Carneos_actualiz_2007-08.pdf, Visitada julio 2010.

6. Olivera Carrión M. Separación de proteínas alimenticias por electroforesis: estudio de los cambios inducidos por el procesado, identificación de especies y detección de proteínas en mezclas. Tesis Doctoral. UBA. Argentina. 1988.

7. López LB. Separación, identificación y cuantificación de proteínas en alimentos procesados. Tesis Doctoral. Universidad de Buenos Aires. Argentina. 2000. 
8. López LB, Greco CB, Binaghi MJ, Mambrín MC y Valencia ME. Identificación y cuantificación de especies vacuna y/o porcina en productos cárnicos frescos por SDS-PAGE. Industria Cárnica Latinoam 2010;. N $163.48-51$.

9. Vázquez N, Dotta MF, Bello M y Binotti S. Identificación de especies de origen animal en productos cárnicos por enzimoinmunoensayo (ELISA); Trabajos completos. [CD-ROM]. XII Congreso
Argentino de Ciencia y Tecnología de Alimentos. Concordia, Entre Ríos. Argentina. 2009.

10. Tepnel. BioKits (Cooked) Species Identification Kits Qualitative tests for the detection of species content in foods/feeds http://www.biokits.com/ moreinfos.html?id=337, Visitada julio 2010.

11. Laemmli U.K. Cleavage of structural proteins during the assembly of the head bacteriophage t4; Nature 1970; 227: 680 - 5. 